・论坛・

\title{
加入《迁徙物种公约》，促进全球迁徙动物保护
}

\author{
蒋志刚 $1,2^{*}$ 张正旺 ${ }^{3}$ 张润志 1,2 马志军 ${ }^{4}$ 初红军 5,6 李义明 1,2 \\ 丁长青 ${ }^{7}$ 赵亚辉 1,2 徐基良 ${ }^{7}$ 平晓鸽 ${ }^{1}$ 曾 岩 ${ }^{1}$ 崔绍朋 ${ }^{8}$ 李 娜 ${ }^{1,2}$ \\ 曹丹丹 ${ }^{1,2}$ 王苏盆 $^{1}$ 徐 婧 $^{1}$ 戚英杰 ${ }^{5}$ 李春旺 1,2 \\ 1 (中国科学院动物研究所动物生态与保护生物学院重点实验室, 北京 100101) \\ 2 (中国科学院大学生命科学学院, 北京 100049) \\ 3 (北京师范大学生物多样性与生态工程教育部重点实验室, 北京 100875) \\ 4 (复旦大学生物多样性与生态工程教育部重点实验室, 上海崇明东滩湿地生态系统国家定位观测研究站 上海 200433) \\ 5 (新疆卡拉麦里山野生有蹄类国家级自然保护区，乌鲁木齐 830000) \\ 6 (新疆大学资源环境学院, 乌鲁木齐 830046) \\ 7 (北京林业大学自然保护与生态学院, 北京 100083) \\ 8 (山西农业大学生命科学学院, 山西晋中 030801)
}

\section{Ratifying Bonn Convention, promoting global conservation of migratory animals}

Zhigang Jiang ${ }^{1,2^{*}}$, Zhengwang Zhang ${ }^{3}$, Runzhi Zhang ${ }^{1,2}$, Zhijun $\mathrm{Ma}^{4}$, Hongjun $\mathrm{Chu}^{5,6}$, Yiming $\mathrm{Li}^{1,2}$, Changqing Ding, Yahui Zhao ${ }^{1,2}$, Jiliang $\mathrm{Xu}^{7}$, Xiaoge Ping ${ }^{1}$, Yan Zeng ${ }^{1}$, Shaopeng $\mathrm{Cui}^{8}$, $\mathrm{Na} \mathrm{Li}^{1,2}$, Dandan $\mathrm{Cao}^{1,2}$, Supen Wang ${ }^{1}$, Jing $\mathrm{Xu}^{1}$, Yingjie Qi ${ }^{5}$, Chunwang $\mathrm{Li}^{1,2}$

1 Key Laboratory of Animal Ecology and Conservation Biology, Institute of Zoology, Chinese Academy of Sciences, Beijing 100101

2 College of Life Sciences, University of Chinese Academy of Sciences, Beijing 100049

3 Ministry of Education Key Laboratory for Biodiversity Science and Ecological Engineering, Beijing Normal University Beijing 100875

4 Ministry of Education Key Laboratory for Biodiversity Science and Ecological Engineering, Coastal Ecosystems Research Station of the Yangtze River Estuary, Fudan University, Shanghai 200433

5 Xinjiang Kalamaili Mountain Wild Ungulate National Nature Reserve, Urumqi 830000

6 College of Natural Resources, Xinjiang University, Urumqi 830046

7 College of Natural Conservation and Ecology, Beijing Forestry University, Beijing 100083

8 College of Life Sciences, Shanxi Agricultural University, Jinzhong, Shanxi 030801

自然界中, 一些野生动物为了受食或繁殖, 会 随着季节沿固定或非固定路线从一处栖息地转换 到另一处栖息地。这些野生动物常常跨越国界进行 长距离的迁徙或洄游, 其生存容易受到迁徙或洄游 路线阻断、过度捕猎/捕捞、气候变化以及受食或繁 殖栖息地丧失和退化的威胁(Wilcove \& Wikelski, 2008)。

《保护野生动物迁徙物种公约》(Convention on the Conservation of Migratory Species of Wild
Animals, CMS)(以下简称《迁徙物种公约》)于 1979 年在波恩签订, 因此也被称为波恩公约 (Bonn Convention), 其目的是保护全球范围内陆地、海洋 和空中整个分布区内迁徙、洄游的野生动物物种。 该公约认定各成员国是该国分布或通过其领土迁 徙、洄游物种的保护主体。《迁徙物种公约》有两 个附录(Appendix)：附录一列入了濒临灭绝的迁徙、 洄游物种, 各缔约方应采取措施严格保护这些物种, 恢复其生境, 减少或消除其迁移、洄游的障碍, 控 
制威胁这些物种的其他因素; 附录二列出了需要或 将显著受益于国际合作保护的迁徙、洄游物种。有 些情况下，同一迁徙物种可同时列入附录一和附录 二。截至2019年9月1日, 该公约共有129个缔约方 (CMS，2019)，包括我国临近的南亚、中亚等“一带 一路”沿线诸多国家。公约秘书处设在德国波恩, 由 联合国环境规划署管理(夏壁堡, 2015)。由于种种原 因, 中国尚未加入该公约(CMS, 2019)。为助力生态 文明建设, 加强迁徙物种保护, 我们建议国家有关 部门尽早考虑加入《迁徙物种公约》。

\section{1 加入《迁徙物种公约》, 有利于保护我国䇋 徙物种，增强我国在世界生物多样性保护中的 权，促进国际合作}

迁徙性野生动物是全球生物多样性的重要组 成部分, 日益受到国际社会的高度关注。保护迁徙 物种对于维护全球生物多样性和生态系统平衡、促 进自然与社会的和谐发展具有重要意义。

中国分布着种类众多、数量巨大的迁徙和洄游 性野生动物, 为它们提供了繁殖、越冬、受食和迁 徙中转的关键栖息地, 其中包括许多跨越国界迁徙 和洄游的野生动物。例如: 雪豹(Panthera uncial) ${ }^{\mathbb{1} 、}$ 普氏野马(Equus ferus)、蒙古野驴(E. hemionus)、我鸟 喉羚(Gazella subgutturosa)、盘羊(Ovis ammon)、丹 顶鹤(Grus japonensis)、黄嘴白鹭(Egretta eulophotes)、大鸨(Otis tarda)、小白额雁(Anser erythropus)、獲 (Falco cherrug)、绿海龟(Chelonia mydas)、 玳琩(Eretmochelys imbricata)、中华白海豚(Sousa chinensis)和鲸鲨(Rhincodon typus)等均是典型跨国 界迁徙物种, 被列入了《迁徙物种公约》附录。

《迁徙物种公约》有众多的缔约国和明确的保 护目标和行动方案, 是一个重要的国际生物多样性 与濒危物种保护的对话平台。该公约建立了一系列 区域组织, 形成了迁徙物种保护的专家网络。例如, “中亚迁徙物种保护倡议”(Central Asia Migratory Species Initiative, CAMI), 在中亚协调开展了雪豹、 蒙古野驴、盘羊等迁徙动物的卓有成效的保护。

中国加入《迁徙物种公约》, 将有权提出其附 录修正案，有利于政府间协调跨越国界迁徙与洄游 物种保护行动, 建立跨国保护区网络, 保护迁徙动

(1) 在《保护野生动物迁徙物种公约》附录中, 学名标注为 Uncia uncial.
物的迁徙与洄游廊道, 引入该公约的保护理念, 动 员中国科学家参与迁徙物种的保护工作。在推动 “一带一路”建设, 积极发展与古代丝绸之路沿线国 家的经济合作伙伴关系，共同打造政治互信、经济 融合、文化包容的利益共同体、命运共同体和责任 共同体的同时，依托《迁徙物种公约》的协商平台 和保护技术规范，为保护中国乃至世界的珍稀濒危 迁徙物种做出贡献。

\section{中国已具备加入《迁徙物种公约》的条作}

中国在保护跨国界迁徙与洄游野生动物物种 方面已经开展了大量工作，取得了巨大成绩。在中 国陆生哺乳动物中，雪豹、普氏野马、蒙古野驴、 我喉羚、盘羊等是中亚重要迁徙物种。我国研究人 员参加了《迁徙物种公约》的“中亚迁徙物种保护 倡议”的系列研究交流，国家主管部门重视跨越国 界的迁徙物种保护, 组织开展了中国边境地区雪 豹、普氏野马、蒙古野驴、我喉羚、蒙古原羚 $(P r-$ ocapra gutturosa)以及盘羊种群与栖息地的监测与 保护，建立了一系列自然保护区，在20世纪末，还 将已经在中国灭绝的普氏野马、高鼻羚羊(Saiga tatarica)重新引入到中国。

中国政府还积极开展迁徙候鸟的保护。据统计, 中国分布有数百种候鸟。每年迁徙季节, 大量候鸟 途经我国来往迁飞于亚洲、欧洲、非洲、大洋洲和 北美洲等数十个国家，其中有超过 5,000 万只水鸟 每年在东亚-澳大利西亚迁徙区迁徙。我国加强了湿 地和森林保护, 建立了候鸟迁飞安全责任制度, 结 合候鸟种群及栖息地保护现状, 强化落实了巡护、 值守等保护管理措施。自20世纪80年代起，中国和 日本、澳大利亚分别签署了 “中日候鸟保护协定”和 “中澳候鸟保护协定”，推动了候鸟研究和保护的国 际交流与合作; 成立了全国鸟类环志中心(http://www. chinanbbc.net/), 为开展候鸟的环志工作以及候鸟 迁徙数据的分享提供了重要平台。2008年，中国加 入了东亚-澳大利西亚候鸟迁飞区伙伴关系(East Asian-Australasian Flyway Partnership), 与该候鸟迁 飞区的相关国家和地区共同分享在候鸟研究、保护 和管理方面的经验。2019年7月，作为东亚-澳大利 西亚候鸟迁飞区上最重要的迁徙中转站，中国盐城 湿地作为黄(渤)海候鸟栖息地的一部分被列入世界 自然遗产。 
中国开展了绿海龟和中华白海豚等海洋洄游 物种的保护，取得了卓有成效的工作。国家主管部 门将海龟和白海豚列为国家重点保护野生动物, 将 鲸鲨核准为国家重点保护野生动物, 制定了保护规 划, 加强了保护执法和科学监测, 建立了海洋和海 岛自然保护区, 保护了海龟产卵场, 开展了海龟人 工繁殖, 保护白海豚的受食繁殖海域和洄游通道, 禁止非法捕捞鲸鲨。

\section{3 中国加入《迁徙物种公约》需要进行的相关 备工作}

《迁徙物种公约》秘书处及其工作人员曾在不 同场合表达了希望中国加入该公约的迫切愿望。中 国作为一个大国, 应审时度势, 认真考虑加入该公 约, 登上这一国际对话与合作交流的平台, 为世界 大国作出表率, 承担保护生物多样性的国际承诺。

2020年2月15-22日，《迁徙物种公约》第十三 次缔约方会议将在印度甘迪纳格尔(Gandhinagar)举 行。会议主题是“迁徙物种连接地球, 让我们一起欢
迎它们回家”。我国应当派观察员参加此次会议，熟 悉议题议案和决策流程。观察员归国后，应向国家 主管部门报告有关情况，主管部门应组织人员讨论 研究加入《迁徙物种公约》的可行性和必要性，分 析加入该公约可能的利与弊，形成报告，供国务院 决策。

综上所述，我们建议国家有关部门启动有关程 序，尽早加入《迁徙物种公约》。

\section{参考文献}

CMS (2019) Convention on the Conservation of Migratory Species of Wild Animals. https://www.cms.int/s. (accesssed on 2019-11-28)

Wilcove DS, Wikelski M (2008) Going, going, gone: Is animal migration disappearing? PLoS Biology, 6, e188.

Xia KB (2015) 36 years of the Convention on the Conservation of Migratory Species of Wild Animals. World Environment, (5), 66-69. (in Chinese) [夏斿堡 (2015) 保护迁徙野生动 物物种公约36年. 世界环境, (5), 66-69.]

(责任编辑: 周玉荣) 